\title{
QUIRÓPTEROS FÓSILES DEL ARAGONIENSE MEDIO DE CASETÓN (TERUEL, ESPAÑA)
}

\author{
Paloma SEVILLA
}

Departamento de Paleontología. Facultad de Ciencias Geológicas e Instituto de Geología Económica, CSIC. Universidad Complutense. E-28040. Madrid.

Sevilla, P. 2002. Quirópteros fósiles del Aragoniense medio de Casetón (Teruel, España). [Fossil Chiroptera from the middle Aragonian of Casetón (Teruel, Spain).] Revista Española de Paleontología, 17(2), $257-268$. ISSN 0213-6937.

\begin{abstract}
The fossil bats of Casetón 1A and 2B from the Calatayud-Daroca Basin, dated as middle Aragonian (Middle Miocene, MN5) are described. Four different taxa are represented; three vespertilionids and a hipposiderid. Eptesicus noctuloides is the dominant species in both localities. It is followed by a small Myotis species, close to Myotis minor from the late Oligocene. A third taxon, with a very low representation at both levels, has been identified as a large sized species of Eptesicus, of a similar size as E. campanensis or even somewhat larger. A single fossil collected at Casetón IA has been identified as a hipposiderid. Its morphology fits with both the genus Asellia and the subgenus Hipposideros (Brachipposideros). Regarding the association of species represented at the two levels in Casetón, no particularity is observed compared with other fluvio-lacustrine localities of similar age in Europe. The occurrence of two Eptesicus species at Casetón l A and Casetón 2B represents the oldest record of this genus in Spain.
\end{abstract}

Keywords: Chiroptera, Vespertilionidae, Hipposideridae, Middle Miocene, Aragonian, Spain.

\section{RESUMEN}

Se describen los fósiles de Quirópteros de las localidades de Casetón I A y Casetón 2B del Aragoniense medio de la cuenca de Calatayud-Daroca. Se han reconocido cuatro taxones diferentes, tres de ellos de la familia Vespertilionidae y el cuarto de la familia Hipposideridae. Tanto en Casetón 1A como en Casetón 2B, Eptesicus noctuloides es la especie mejor representada. Le sigue en importancia una especie de pecueño tamaño del género Myotis, próxima desde el punto de vista morfológico a la especie del Oligoceno terminal Myotis minor. Entre los taxones de menor representación, se han identificado restos de otra especie perteneciente al género Eptesicus, caracterizados por ser de talla grande, igual o incluso superior a la de E. campanensis. Por último, un único resto procedente de Casetón $1 \mathrm{~A}$ representa a la familia Hipposideridae, y encaja en la morfología del género Asellia y del subgénero Hipposideros (Brachipposideros). Las asociaciones registradas en Casetón $1 \mathrm{~A}$ y $2 \mathrm{~B}$, en las que los vespertiliónidos dominan, no difieren sustancialmente de las asociaciones registradas en yacimientos europeos fluvio-lacustres de edad similar. Las dos especies pertenecientes al género Eptesicus identificadas en Casetón IA y $2 \mathrm{~B}$ constituyen el registro más antiguo de este género en España.

Palabras clave: Chiroptera, Vespertilionidae, Hipposideridae, Mioceno Medio, Aragoniense, España.

\section{INTRODUCCIÓN}

La cuenca de Calatayud-Daroca constituye una cuenca excepcional para el estudio de mamíferos fósiles. Los muestreos sistemáticos llevados a cabo por los equipos dirigidos por los dres. R. Daams y M. Freudenthal desde el año 1976 en esta región han tenido como resultado la descripción de más de un centenar de localidades con micromamíferos que han permitido definir dos pisos continentales para el Mioceno: el
Rambliense y el Aragoniense, correlacionables con las escalas descritas para el Mioceno continental de Europa (Daams et al., 1987; Daams et al., 1999). El fruto del intenso trabajo desarrollado en esta cuenca ha quedado reflejado en numerosísimos trabajos que abordan, además del estudio sistemático de los fósiles recogidos, la bioestratigrafía, sedimentología y paleoecología del Mioceno Inferior y del Mioceno Medio de la región, que quedan resumidos en algunos trabajos recientes de síntesis (Daams et al., 1999; Alcalá et al., 2000). 


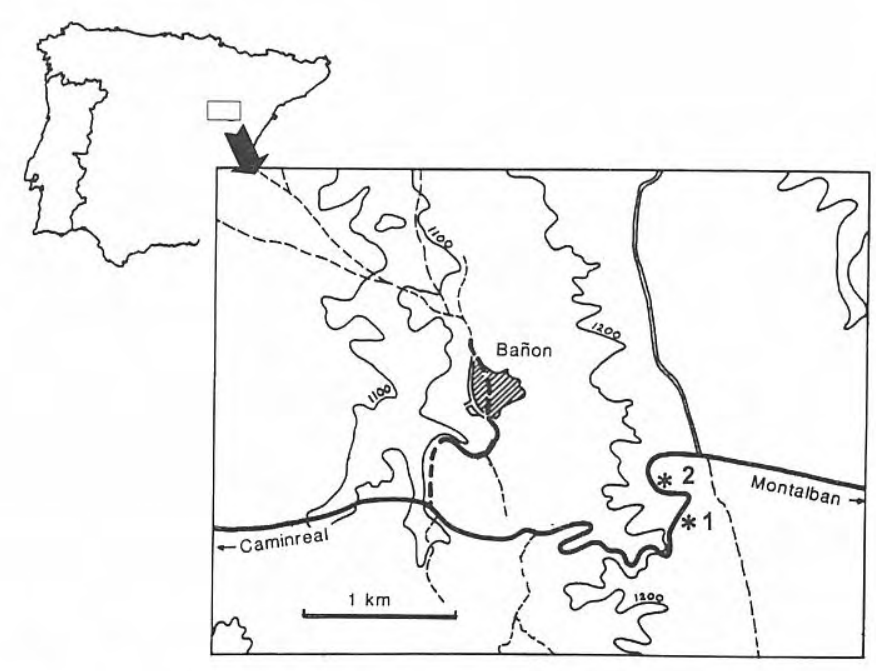

Figura 1. Mapa del área de Bañón mostrando la situación de los yacimientos de Casetón 1A $(\star 1)$ y de Casetón 2B ( $\star 2$ ). (Modificado de Daams y Freudenthal, 1988.)

Map of the Bañon area showing the localities of Casetón 1A ( $\star 1)$ and Casetón $2 B(\star 2)$. (Modified from Daams and Freudenthal, 1988.)

Casetón 1A y Casetón 2B son dos niveles fosilíferos situados en la sección de Bañón, en el área de DarocaCalamocha (Fig. 1). Entre los abundantes restos de micromamíferos recogidos en ambos niveles, dominan los roedores y más particularmente los cricétidos modernos, con porcentajes menores de glíridos y algún esciúrido (Van der Meulen y Daams, 1992). A partir de esta fauna se les asignó una edad de Aragoniense medio, concretamente de la zona D1 de la zonación local (Daams y Freudenthal, 1988), Db en una revisión posterior, correlacionable con la zona MN 5 de Mein (Daams et al., 1999).

Como es habitual en los yacimientos fluvio-lacustres con micromamíferos, los quirópteros constituyen una fauna pobremente representada en estas dos asociaciones, ya que representan no más de un $0,01 \%$ frente al número de restos de roedores (véase figura 8 en Daams et al., 1988). No obstante, los 24 restos de quirópteros identificados en Casetón 1A y los 21 de Casetón 2B constituyen una aportación de interés a la escasamente caracterizada fauna de quirópteros del Mioceno de España.

Este trabajo está dedicado a la memoria de nuestro muy apreciado compañero, el prof. Remmert Daams, iniciando con ello el cumplimiento de un compromiso hace tiempo contraído: el de estudiar los quirópteros fósiles recogidos en sus campañas de excavación.

\section{ANTECEDENTES}

Los datos disponibles sobre el registro de quirópteros en el Mioceno español son muy escasos. Contrasta con los abundantes datos y la buena documentación disponible de otros grupos de micromamíferos, y en particular de roedores. Esto se debe a la baja proporción en la que están representados los murciélagos en la mayoría de los yacimientos y a la alta fragmentación de los restos que dificulta enormemente su determinación taxonómica. Como consecuencia, salvo contadas excepciones, los datos disponibles se limitan a referencias taxonómicas imprecisas en las listas faunísticas de las localidades.

Aún así, hay citas de varios géneros actuales en el Mioceno de España. Uno de los más frecuentes es el género Myotis, citado en diversas localidades del Mioceno Inferior, como Fuenmayor (MN2) (Martínez Salanova, 1987), Navarrete del Río (MN3) (Adrover, 1972), del Mioceno Superior como Los Aguanaces (MN11), Vivero de los Pinos (MN11) (Adrover, 1975). El género Rhinolophus está citado desde el Mioceno Medio de Navarrete del Río (Adrover, op. cit.), Cosa (MN3) (Adrover et al., 1978) y Escobosa (MN7/8) (Sesé, 1986), y se ha reconocido también en el Mioceno Superior de Puente Minero (MN11) (Alcalá et al., 1991), Salobreña (MN13) (Aguilar et. al., 1984) y Cal es Pous (MN13) (Agustí y Moyà-Solà, 1990).

Otro género actual, poco frecuente en los yacimientos, pero registrado desde el Mioceno Medio en España, Tadarida, se ha citado en Buñol (MN4) (Adrover, 1968) y Salobreña (Aguilar et al., op. cit.). El género Miniopterus, conocido en Europa desde el Mioceno Medio, tiene su primer registro en España en el yacimiento de Salobreña. Por otro lado, persisten, al menos hasta el Mioceno Medio, géneros de formas subtropicales más frecuentes en el Oligoceno, como la especie del género Megaderma citada en el yacimiento de Escobosa (Sesé, 1986).

Salvo en el caso de los yacimientos de Fuenmayor y de Escobosa, en los que los restos de quirópteros están descritos, figurados y medidos, las citas anteriormente comentadas se limitan a referencias en listas faunísticas, por lo que su comparación con restos de otros yacimientos resulta imposible.

El registro de quirópteros del Mioceno en otros países de Europa occidental y Centroeuropa es más completo y está mejor documentado. Hay datos de quirópteros fósiles a lo largo de prácticamente todo el Mioceno (véase Storch, 1999), durante el cual se comprueba la importante influencia que ejerce el tipo de yacimiento sobre las especies representadas en las asociaciones. Así, como señalan Sigé y Legendre en su trabajo de 1983, las asociaciones procedentes de yacimientos cársticos parecen dominadas por especies de la superfamilia Rhinolophoidea, mientras que en los yacimientos fluviolacustres suelen dominar especies pertenecientes a la familia de los Vespertilionidae.

\section{MATERIAL Y MÉTODOS}

El material descrito en este trabajo pertenece a las colecciones del Rijksmuseum van Geologie en Mineralogie de Leiden (Holanda). Los restos de quirópteros procedentes de Casetón 1A se identifican con las siglas RGM 413935 a 

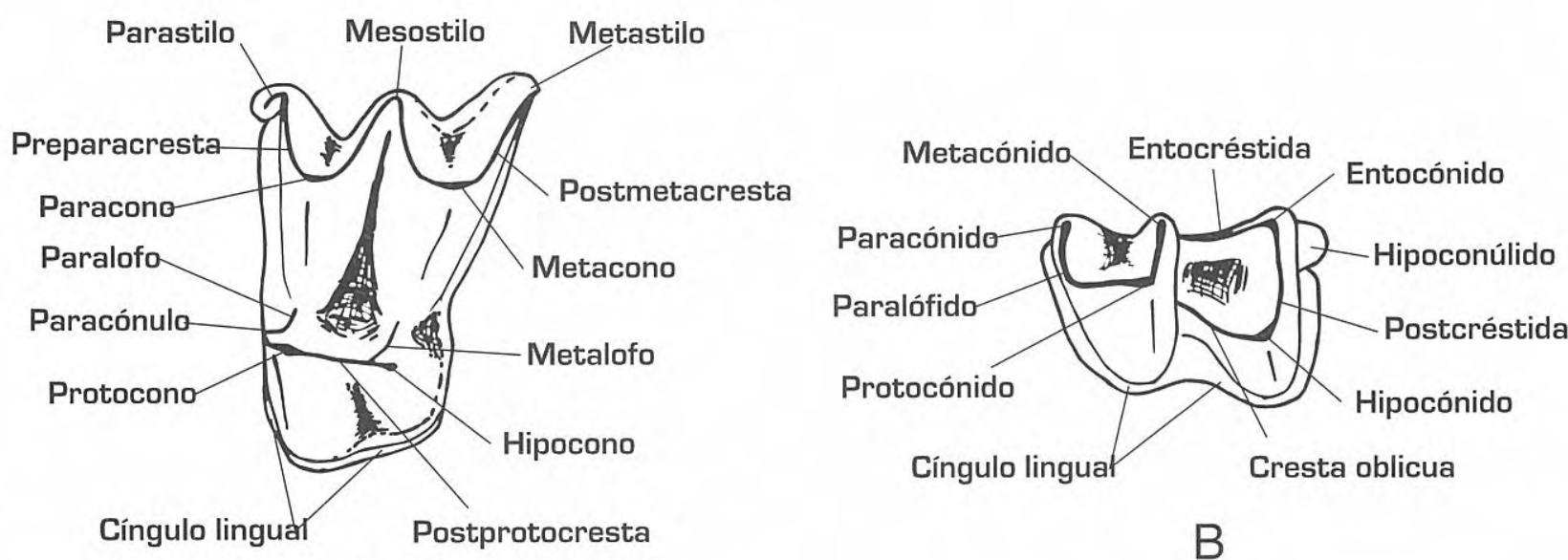

A

Figura 2. Nomenclatura de los molares superiores (A) e inferiores (B) de quirópteros. (Según Van Valen, con modificaciones de Rachl, 1983 y Menú,1985.)

Nomenclature of upper (A) and lower molars (B) of chiroptera. (After Van Valen, modified by Rachl, 1983 and Menú, 1985.)

RGM 413960; los procedentes de Casetón 2B con las de RGM 413961 a RGM 413981. La totalidad del material de quirópteros de ambos yacimientos consiste en restos de dientes aislados, frecuentemente con algún tipo de deterioro, como la pérdida por rotura de las raíces, los estilos o incluso con el esmalte corroído.

La figura 1 muestra los términos utilizados en este trabajo para describir los caracteres de la morfología de los molares de quirópteros. Dado que los fósiles más frecuentes de quirópteros son sus dientes aislados, hay en la bibliografía diversos trabajos dedicados a describir los

\begin{tabular}{|c|c|c|c|c|c|}
\hline & & $n$ & L & A & a \\
\hline$M^{1}$ & CS2B & 1 & 1,21 & 1,41 & \\
\hline$M^{2}$ & CS2B & 1 & 1,25 & 1,52 & \\
\hline \multirow{2}{*}{$\mathbf{M}^{3}$} & CS1A & 1 & 1,01 & 1,45 & \\
\hline & CS2B & 1 & - & - & \\
\hline$C$ inf. & CS1A & 2 & $0,78-0,82$ & $0,70-0,74$ & \\
\hline$M_{1}$ & CS1A & 2 & $1,13-1,15$ & - & - \\
\hline $\mathbf{M}_{2}$ & CS1A & 2 & 1,05 & 0,70 & $0,74-0,78$ \\
\hline $\mathbf{M}_{3}$ & CS1A & 2 & $1,01-1,05$ & 0,70 & 0,54 \\
\hline
\end{tabular}

Tabla 1. Medidas de Myotis aff. minor de Casetón 1A (CS1A) y Casetón 2B (CS2B). ( $n=$ número de restos; $\mathrm{L}=$ longitud; $\mathrm{A}=$ anchura; en molares inferiores, anchura del trigónido; $\mathrm{a}=$ anchura del talónido.)

Measurements of Myotis aff. minor from Casetón $1 A(C S 1 A)$ and Casetón $2 B(C S 2 B)$. $(n=$ number of remains; $L=$ length; $A=$ width; in the lower molars, the width of the trigonid; $a=$ width of the talonid.) caracteres más significativos para reconocer las especies y los géneros a partir de su morfología dentaria (Sevilla, 1986, Sevilla y López Martínez, 1986; Menú y Popelard, 1987), e incluso a establecer la polaridad de estos caracteres para realizar análisis filogenéticos (Menú, 1985, 1987). De los numerosos caracteres que se exponen en estos trabajos, sólo se ha hecho referencia en las descripciones del material de Casetón 1A y Casetón 2B a aquellos que resultan relevantes para caracterizar los taxones representados.

No hay uniformidad de criterio entre los autores en cuanto a la forma de medir los dientes en quirópteros. Algunos autores miden las longitudes y anchuras perpendiculares entre sí (Sigé, 1968; Rachl, 1983), mientras que otros las realizan desde puntos de referencia fijos, tales como la base de algunas cúspides, los estilos, el final de las crestas, etc. (Storch, 1974). Las medidas de las Tablas 1 a 4 se han realizado siguiendo los criterios expuestos en Sevilla (1988), es decir, desde puntos de referencia fijos. Las diferencias de los valores obtenidos siguiendo uno u otro criterio de medida son poco significativas, salvo para el caso de la longitud del $\mathrm{M}^{3}$. En este diente, el grado de reducción del ectolofo es un carácter sistemático importante y queda mejor reflejado cuando la longitud se mide desde el parastilo hasta el final de la postmetacresta, que si se miden la longitud y la anchura perpendiculares entre sí.

\section{ESTUDIO SISTEMÁTICO}

\author{
Familia Vespertilionidae Miller, 1897 \\ Myotis Kaup, 1829
}

Myotis aff. minor Ziegler, 2000 b Fig. 3

Material: Casetón 1A: $1 \mathrm{M}^{3}, 2 \mathrm{C}$ inf, $2 \mathrm{M}_{1}, 2 \mathrm{M}_{2}, 2 \mathrm{M}_{3}$. Casetón 2B: $1 \mathrm{M}^{1}, 1 \mathrm{M}^{2}, 1 \mathrm{M}^{3}$.

Medidas: Tabla 1. 


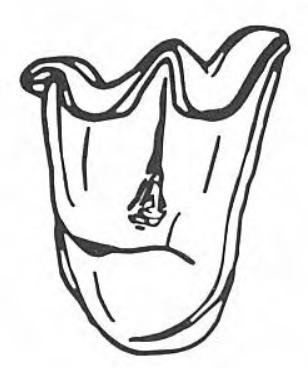

a

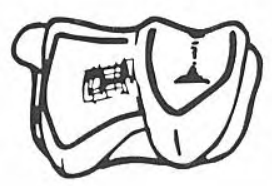

i
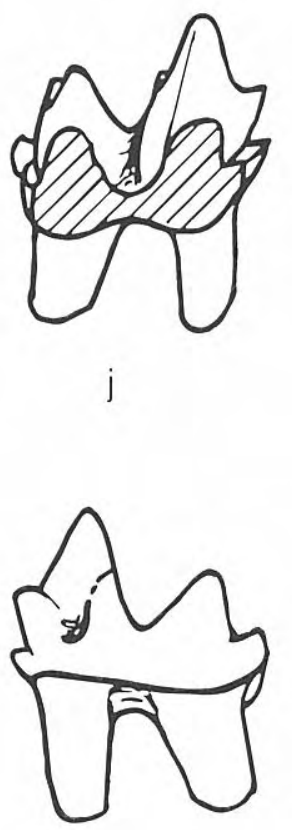

k

$1 \mathrm{~mm}$

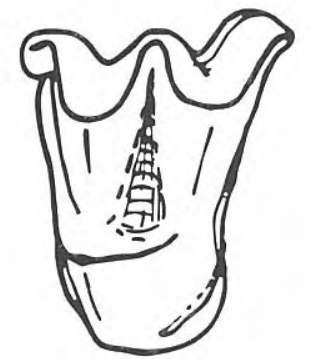

b

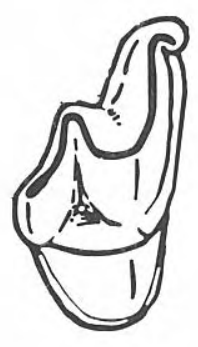

C
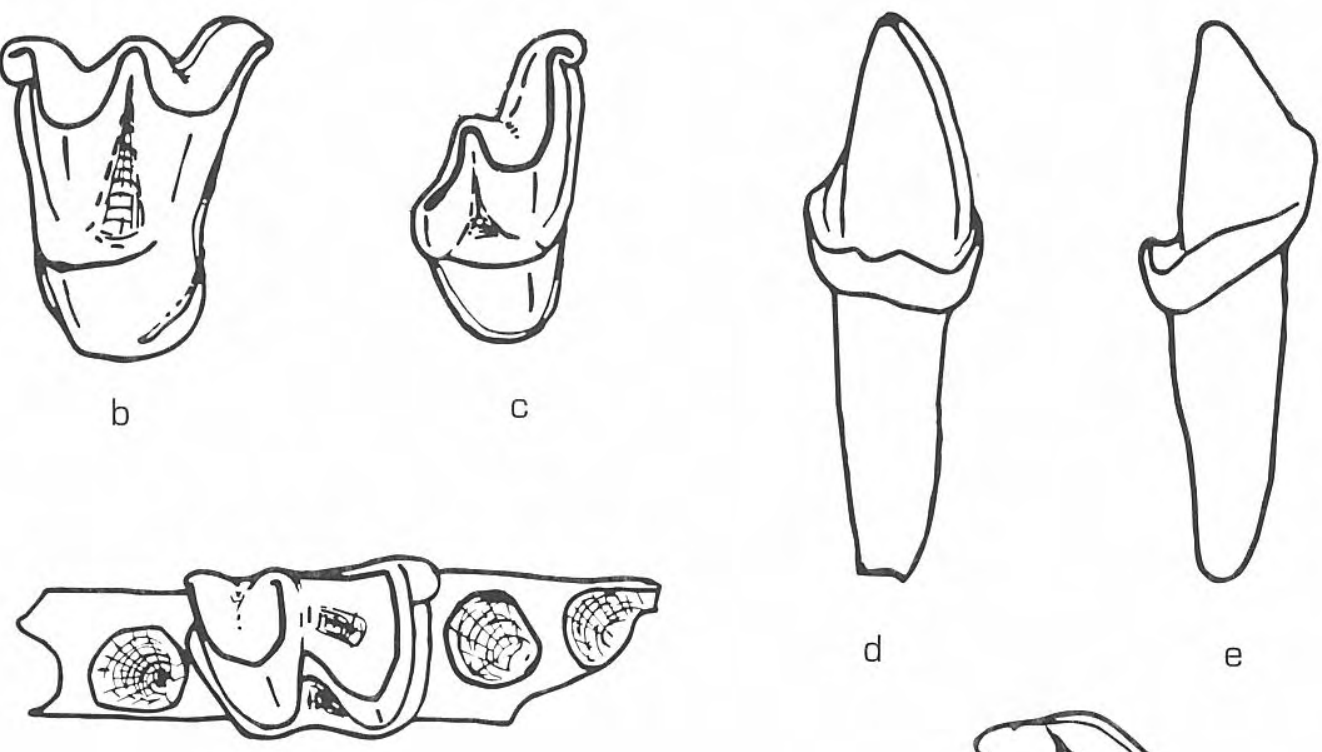

d

e
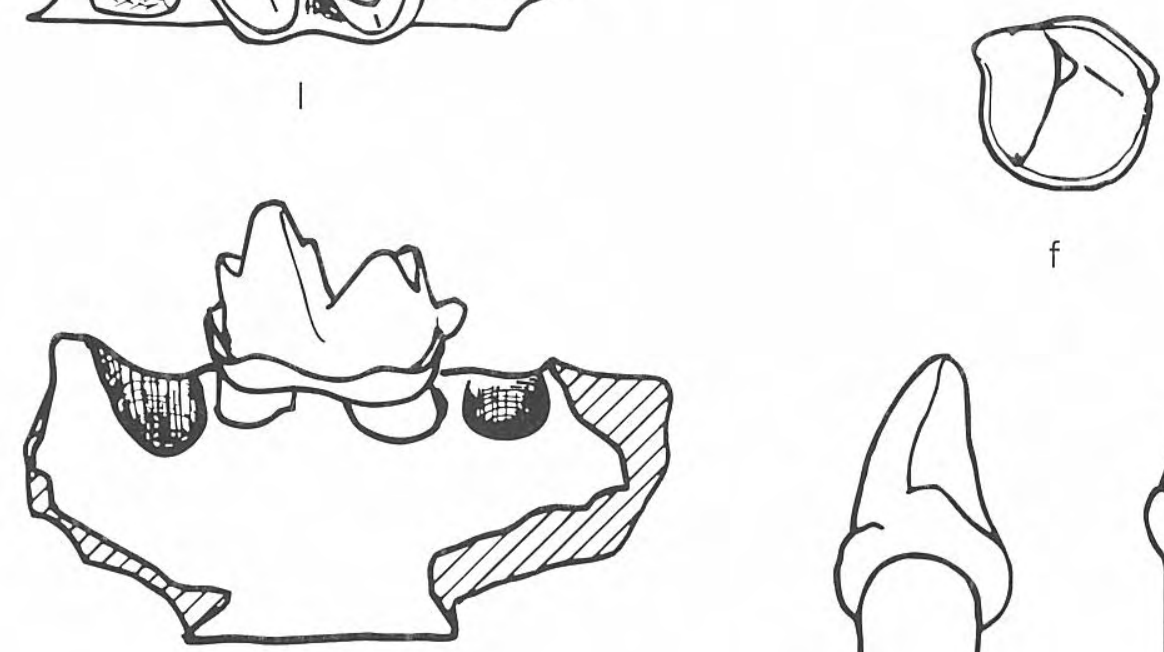

$\mathrm{m}$

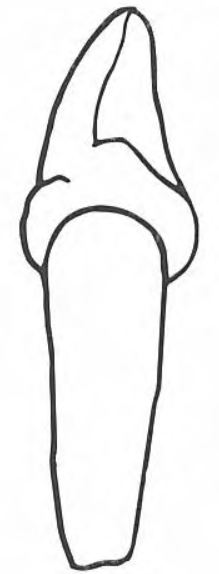

g

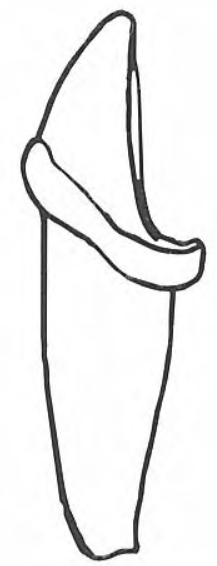

h

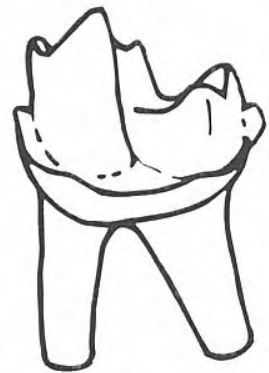

$\mathrm{n}$

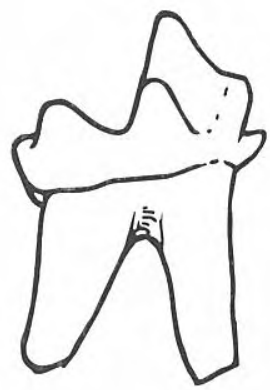

0

\section{f}

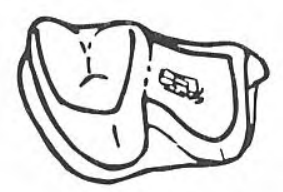

$\mathrm{p}$

Figura 3. Myotis aff. minor. a: $M^{\prime}$ izdo (RGM 413968). b: $M^{2}$ izdo. (RGM 413965). c: $M^{3}$ dcho. (RGM 413951). d-h: C inf. dcho. (RGM 413941) (d: vista distal; e: vista labial; f: vista oclusal; g: vista proximal; h: vista lingual). i-k: M, dcho. (RGM 413955) (i: vista oclusal; j: vista labial; k: vista lingual). l-m: fragmento de mandíbula izda. con $\mathrm{M}_{2}$. (RGM 413942) (l: vista oclusal; m: vista labial). n-p: $M_{3}$ izdo. (RGM 413956) (n: vista labial; o: vista lingual; p:vista oclusal).

Myotis aff. minor. $\boldsymbol{a}$ : left $M^{\prime}$ (RGM 413968). $\boldsymbol{b}$ : left $M^{2}$ (RGM 413965). $\boldsymbol{c}$ : right $M^{3}$ (RGM 413951). $\boldsymbol{d}$-h: right lower $C$ (RGM 413941) (d: distal view; e: labial view; $f$ : occlusal view; g: proximal view; h: lingual view). i-k: right $M_{1}$ (RGM 413955) (i: occlusal view; $j$ : labial view; k: lingual view). l-m: fragment of left mandible with $M_{2}$. (RGM 413942) (l: occlusal view; m: labial view). n-p: left $M_{3}$ (RGM 413956) (n: labial view; o: lingual view; p: occlusal view). 


\section{Descripción}

$\mathbf{M}^{\mathbf{1}}$ : contorno trapezoidal, la mitad lingual redondeada. Las crestas del ectolofo de tamaño creciente en sentido distal. Paralofo casi inapreciable; el metalofo, algo más marcado, se une a la postprotocresta marcando un esbozo de metacónulo. Sin hipocono. El cíngulo lingual se interrumpe brevemente en la base del protocono.

$\mathbf{M}^{2}$ : contorno subrectangular. Postmetacresta alargada, las restantes crestas del ectolofo de desarrollo equivalente. Paralofo casi inapreciable. Postprotocresta recurvada hacia la base del paracono; del final de la postprotocresta surge un débil metalofo hacia la base del metacono, cerrando distalmente la protofosa. El cíngulo lingual se interrumpe brevemente en la base del protocono.

$\mathbf{M}^{3}$ : contorno triangular. Con un débil paralofo. Postparacresta ligeramente más corta que la premetacresta. Metacono presente. Postprotocresta dirigida hacia la base anterior del metacono. Cíngulo lingual continuo en la base del protocono.

C inferior: contorno circular en vista oclusal. La cúspide principal es gruesa y presenta tres aristas. Entre las aristas anterior y posterolabial queda delimitada una superficie convexa; la superficie distal es ligeramente cóncava y la superficie lingual es cóncava en su tercio anterior y convexa en los dos tercios posteriores. El grosor del cíngulo es máximo en la cara labial; discurre continuo por toda la base del diente, salvo en el extremo anterior. El cíngulo lingual comienza en su parte anterior con un ligero engrosamiento que forma una cúspide basal accesoria. En el ángulo distolingual del cíngulo se desarrolla otra cúspide accesoria baja.

$\mathbf{M}_{1}$ : molar myotodonto (Menú y Sigé, 1971). Paracónido y metacónido próximos; metacónido ligeramente más alto que el paracónido. Protolófido alto y recurvado. Talónido netamente más ancho que el trigónido. Entocréstida recta. Hipoconúlido grande.

$\mathbf{M}_{2}$ : muy similar al $\mathbf{M}_{1}$, pero ligeramente más largo, con el trigónido algo más ancho y con el paracónido y metacónido más próximos entre sí, dejando un valle lingual más cerrado. Cíngulo de grosor irregular.

$\mathbf{M}_{3}$ : talónido medianamente reducido. El protolófido está ligeramente reducido. Entocónido ligeramente desplazado labialmente y algo reducido en altura. Hipocónido en la misma posición que en los molares anteriores, pero reducido en altura. Postcréstida reducida a casi la mitad de la del $\mathrm{M}_{2}$. Hipoconúlido reducido a la mitad del tamaño que en el $M_{1}$ y $\mathrm{M}_{2}$. Cíngulo recurvado en vista labial, de modo que su punto más bajo se da en el paso del trigónido al talónido.

\section{Discusión}

Los caracteres observados en estos fósiles encajan en la morfología dentaria que presentan las especies de pequeña talla del género Myotis. Éste es el género más frecuente de vespertiliónido en el Mioceno.

El material de Casetón 1A y Casetón 2B asignado al género Myotis es similar en talla al que presentan dos especies descritas por Baudelot (1972) en el yacimiento del Mioceno Medio de Sansan (MN6), $M$. murinoides y $M$. elegans. M. murinoides (Lartet, 1851) presenta una morfología similar a la del material de Casetón 1A y
Casetón 2B, pero con algunas diferencias significativas que excluyen su pertenencia a la misma especie. Así, $M$. murinoides presenta mesocónido en los molares inferiores, una escotadura profunda en el paralófido del $\mathrm{M}_{1} \mathrm{y}$ una pequeña cresta une el hipoconúlido con el entocónido; los caninos inferiores son más alargados distalmente; los molares superiores presentan paralofo y metalofo bien desarrollados, el cíngulo es continuo en la base del protocono y en el $\mathrm{M}^{1}$ el contorno lingual es más alargado por presentar el hipocono bien desarrollado. Estos mismos caracteres se observan en $M$. aff. murinoides de Stubersheim 3 (MN3) (Ziegler, 1994) y de Sandelzhausen (MN5) (Ziegler, 2000a) y en cambio no se dan ni en el material procedente de Casetón 1A ni en el de Casetón 2B.

M. elegans Baudelot, 1972, de Sansan, se conoce a partir de un fragmento de mandíbula con un $\mathrm{P}_{4} \mathrm{y}$ dos dientes aislados: un $M_{1}$ y un $M^{1-2}$. Esta especie se caracteriza por la gracilidad de la mandíbula, aspecto que no se observa en el ejemplar RGM 413943, el único resto entre el material estudiado que conserva un fragmento de mandíbula. Además, el trigónido del $\mathrm{M}_{1}$ en $M$. elegans es más abierto, con una escotadura profunda en el paralófido y el protolófido proporcionalmente más corto que en el material de Casetón 1A y Casetón 2B. El único molar superior descrito de $M$. elegans (Baudelot, op. cit.) es peculiar en el sentido de que presenta el protocono alto y muy adelantado, en una posición algo más mesial que la del paracono. Ninguno de estos caracteres se observan en los restos asignados al género Myotis en Casetón 1A y Casetón 2B, por lo que no pueden atribuirse a esta especie.

$M$. boyeri Mein, 1964, descrita en el yacimiento francés de Lissieu del Mioceno Superior (MN13) (Mein, 1964), también es de talla próxima a la de las poblaciones de Casetón, pero presenta importantes diferencias morfológicas. En los molares inferiores el trigónido es más abierto y la entocréstida corta; el talónido del $\mathrm{M}_{3}$ está proporcionalmente poco reducido. En el único molar superior descrito se observa una morfología peculiar para un representante del género Myotis: la postprotocresta se une al cíngulo distal; el metacono, con las crestas reducidas en longitud, está en una posición más labial que el paracono; del protocono sale una cresta hacia la protofosa.

Sigé (1968) describió dos especies del género Myotis del Mioceno inferior de Bouzigues (MN2), Myotis sp. I y Myotis sp. II, que por falta de material suficiente quedaron en nomenclatura abierta. Tampoco coincide la morfología de ninguna de ellas con la del material del género Myotis de Casetón 1A y Casetón 2B. Así, Myotis sp. I, aunque de tamaño similar, presenta molares superiores proporcionalmente más cortos y anchos, el paralofo y el metalofo están bien desarrollados y en su contacto con las crestas del protocono se observa un esbozo de paracónulo y de metacónulo. En vista oclusal, el contorno presenta una concavidad marcada en el margen distal entre la base del metacono y el final de la postprotocresta, que no se observa en el material de Casetón 2B. El único resto de quiróptero del yacimiento fluvio-lacustre de Fuenmayor se ha relacionado con esta especie de Bouzigues (Martínez Salanova, 1987). 
Myotis sp. II, representada únicamente por un $\mathrm{M}^{1} \mathrm{y}$ un $\mathrm{M}^{2}$ en Bouzigues (Sigé, 1968) es claramente de mayor talla y presenta molares superiores con paralofo y sin metalofo; la postprotocresta del $\mathrm{M}^{\top}$ discurre en dirección lingual desde el protocono, y además presenta un hipocono bien desarrollado.

M. antiquus (Gaillard, 1899) es también más grande. Esta forma es difícil de comparar a partir de su definición original; Myotis aff. antiquus de Stubersheim 3 (Ziegler, 1994) muestra una morfología muy diferente de la del material de Myotis de Casetón 1A y Casetón 2B: los molares inferiores presentan una escotadura profunda tanto en el protolófido como en el paralófido. El talónido es corto, en los $\mathrm{M}_{3}$ el talónido está fuertemente reducido y no hay hipoconúlido. Los molares superiores también son más cuadrados; el parastilo está muy desarrollado al igual que todo el cíngulo. En el $\mathrm{M}^{3}$ se observa una importante reducción distal, siendo la premetacresta más corta que la postparacresta.

Recientemente, Ziegler (2000b) ha descrito una especie nueva, $M$. minor, procedente de los rellenos cársticos Herrlingen 8 y 9 (MP 29) del Oligoceno terminal del sur de Alemania. Al comparar esta especie con el material de Myotis de Casetón 1A y 2B, se observa una gran proximidad tanto en la morfología como en la talla, marcada no obstante por algunas diferencias. Así, el material de Herrlingen se caracteriza por presentar caninos inferiores más alargados, la cúspide principal es más baja y las cúspides basales mucho más desarrolladas que en los caninos inferiores de Casetón 1A atribuidos a Myotis; el $\mathrm{M}_{3}$ de M. minor presenta una gran reducción del hipoconúlido que no se observa en el $\mathrm{M}_{3}$ de Casetón $1 \mathrm{~A}$, y en los $\mathrm{M}^{1-2}$ de $M$. minor el paralofo y el metalofo están bien desarrollados, mientras que en los molares superiores, procedentes de Casetón 2B, solo se observa bien desarrollado el paralofo en el $\mathrm{M}^{1}$. Por todo ello creemos que se trata de una especie muy próxima morfológicamente a $M$. minor, pero no la misma. El material del género Myotis de Casetón 1A y Casetón $2 \mathrm{~B}$ es insuficiente para caracterizar una especie nueva, por lo que se la denomina provisionalmente $M$. aff. minor.

Eptesicus Rafinesque, 1820

\section{Eptesicus noctuloides (Lartet, 1851)} Fig. 4
Material: Casetón 1A: $2 \mathrm{C}$ sup., $2 \mathrm{M}^{1}, 3 \mathrm{M}^{2}, 1 \mathrm{M}^{3}, 1 \mathrm{M}_{\mathrm{l}}, 2 \mathrm{M}_{2}$. Casetón $2 \mathrm{~B}$ : $1 \mathrm{C}$ sup., $2 \mathrm{M}^{1}, 5 \mathrm{M}^{2}, 2 \mathrm{M}^{3}, 1 \mathrm{C}$ inf, $1 \mathrm{P}_{4}, 2 \mathrm{M}_{1}, 1 \mathrm{M}_{2}$, $2 \mathrm{M}_{3}$.

\section{Medidas: Tabla 2.}

\section{Descripción}

C superior: contorno semicircular en vista oclusal. La cúspide, ligeramente recurvada distalmente, presenta dos crestas, una anterolingual y otra distal. La superficie lingual entre las dos crestas es suavemente cóncava. La superficie anterior y labial es fuertemente convexa, con un surco anterior que se atenúa hacia el ápice y otro más profundo en el tercio posterior, que se desarrolla hasta el mismo ápice. El cíngulo es continuo, algo más grueso en la región labial y anterolingual. A nivel de la arista anterior presenta una cúspide basal bien marcada.

$\mathbf{M}^{1}$ : contorno trapezoidal, el diente se ensancha distalmente. El cíngulo se interrumpe en la base del protocono. Metacono aproximadamente el doble de alto que el paracono. Paralofo y metalofo bien desarrollados. La postprotocresta se recurva en dirección lingual detrás del metalofo; al final se observa un esbozo de hipocono.

$\mathbf{M}^{2}$ : similar al $\mathbf{M}^{1}$, pero con el borde labial más comprimido y contorno subrectangular. La postprotocresta se recurva hacia el metacono, pero se interrumpe antes de llegar a su base. Sin hipocono.

$\mathbf{M}^{3}$ : diente de contorno triangular. La base del metacono sobresale en vista oclusal como un lóbulo distal. La postparacresta es más corta que la premetacresta. El paralofo es de desarrollo variable. El cíngulo lingual se interrumpe en la base del protocono. La postprotocresta se dirige hacia el metacono y termina en la base anterior de éste.

C inferior: contorno semicircular; más ancho que largo. Las dos aristas distales delimitan la superficie distal aplanada. La superficie labial es convexa y la lingual es cóncava en la mitad anterior y convexa en la mitad posterior. El cíngulo, de grosor irregular, discurre continuo alrededor de todo el diente. En su parte anterior desarrolla una cúspide basal de la que parte una suave arista hacia el ápice de la cúspide principal.

$\mathbf{P}_{4}$ : diente de contorno subcuadrado en vista oclusal. Provisto de dos raíces. La cúspide principal, en posición centrada, presenta, al igual que en el canino, tres aristas que delimitan una superficie labial convexa, una distal cóncava y una superficie lingual cóncavo-convexa. Con dos cúspides basales accesorias en los ángulos internos anterior y posterior del cíngulo.

Figura 4. Eptesicus noctuloides. a-c: C sup. izdo. (RGM 413938) (a: vista labial; b: vista lingual; c: vista oclusal). d: $\mathrm{M}^{3}$ dcho. (RGM 413978). e: $M^{2}$ dcho. (RGM 413940). f: $M^{1}$ dcho. (RGM 413966). g-i: $P_{4}$ izdo. (RGM 413973) (g: vista labial; h: vista oclusal; i: vista distal). j-n: C inf. dcho. (RGM 413962) (j: vista distal; k: vista labial; 1: vista oclusal; $\mathrm{m}$ : vista proximal; $\mathrm{n}$ : vista lingual). o-q: $\mathrm{M}_{1}$ izdo. (RGM 413970) (o: vista oclusal; $\mathrm{p}$ : vista labial; q: vista lingual). $\mathbf{r}$ t: $M_{2}$ dcho. (RGM 413952) (r: vista oclusal; s: vista labial; t: vista lingual). u-w: $M_{3}$ dcho. (RGM 413975) (u: vista oclusal; v: vista labial; w: vista lingual).

Eptesicus noctuloides. a-c: left upper C (RGM 413938) (a: labial view; b: lingual view; $c$ : occlusal view). d: right $M^{3}$ (RGM 413978). e: right $M^{2}$ (RGM 413940). f: right $M^{\prime}$ (RGM 413966). g-i: left $P_{4}$ (RGM 413973) (g: labial view; $h$ : occlusal view; $i$ : distal view). $j$-n: right lower $C$ (RGM 413962) ( $j$ : distal view; $k$ : labial view; l: occlusal view; $m$ : proximal view; $n$ : lingual view). o-q: left $M_{I}(R G M$ 413970) (o: occlusal view; $p$ : labial view; q: lingual view). $\boldsymbol{r}$-t: right $M_{2}\left(R G M\right.$ 413952) (r: occlusal view; s: labial view; $t$ : lingual view). $u$-w: right $M_{3}(R G M$ 413975) (u: occlusal view; v: labial view; w: lingual view). 

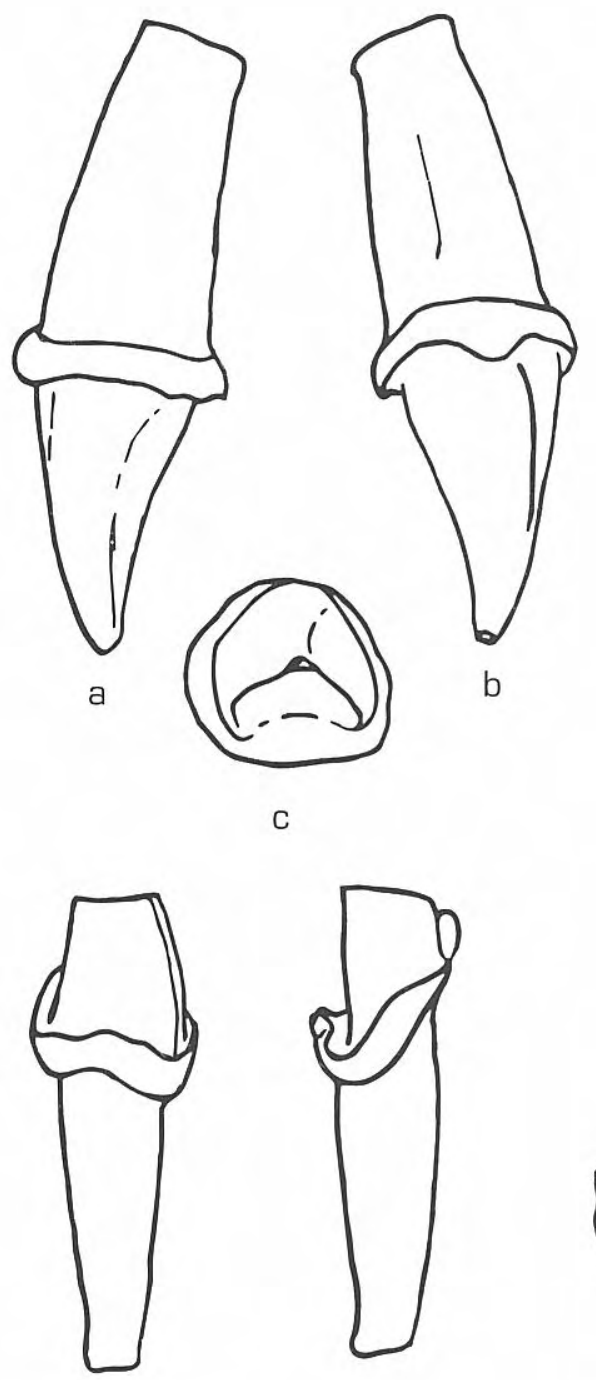

k
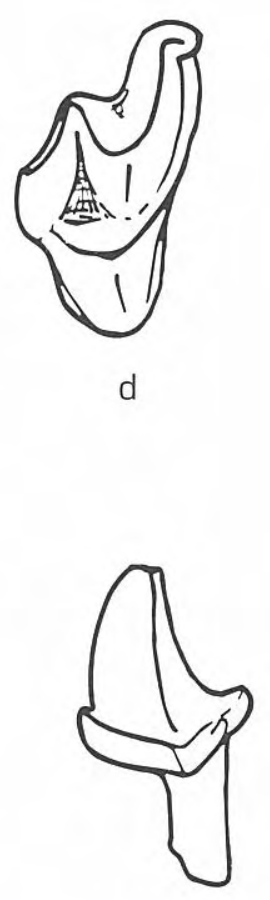

g
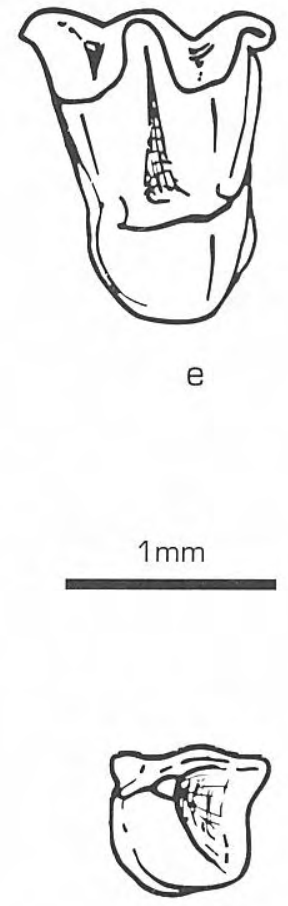

h

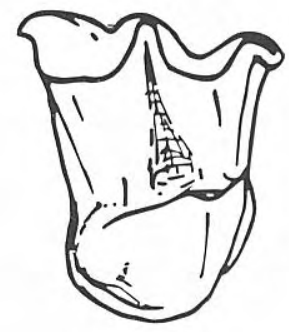

f
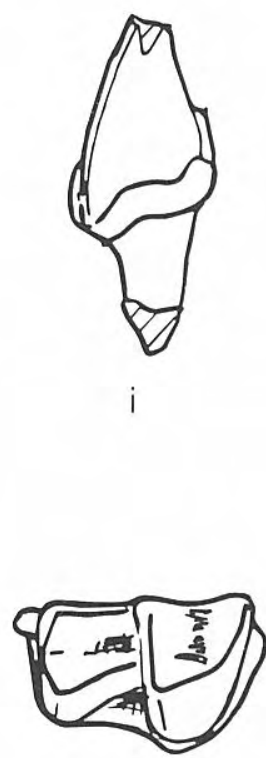

u

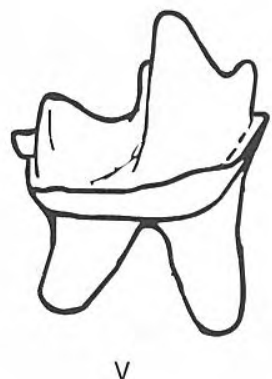

$\mathrm{p}$

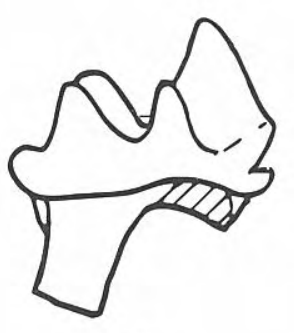

q
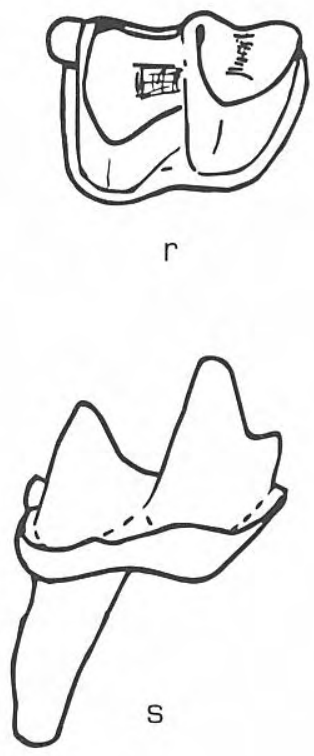

r

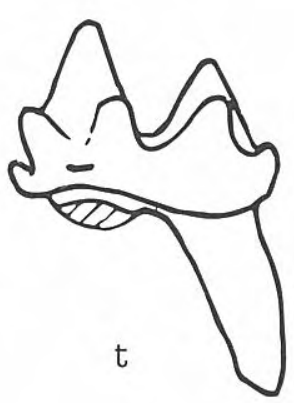

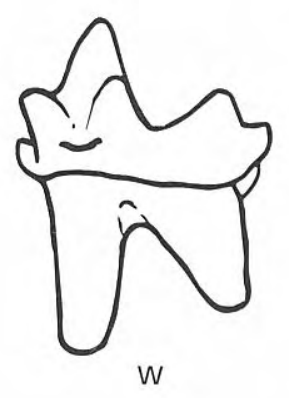




\begin{tabular}{|c|c|c|c|c|c|}
\hline & & $\mathrm{n}$ & L & A & a \\
\hline \multirow{2}{*}{$C$ sup. } & CS1A & 2 & $0,94-1,01$ & $0,78-0,84$ & \\
\hline & $\mathrm{CS} 2 \mathrm{~B}$ & 1 & 1,05 & 0,86 & \\
\hline \multirow{2}{*}{$\mathbf{M}^{1}$} & CS1A & 2 & $1,29-1,37$ & $1,37-1,45$ & \\
\hline & $\mathrm{CS} 2 \mathrm{~B}$ & 2 & $1,25-1,29$ & $1,41-1,47$ & \\
\hline \multirow{2}{*}{$M^{2}$} & CS1A & 3 & 1,21 & $1,45-1,52$ & \\
\hline & $\mathrm{CS} 2 \mathrm{~B}$ & 5 & - & 1,50 & \\
\hline \multirow{2}{*}{$M^{3}$} & $\operatorname{CS} 1 \mathrm{~A}$ & 1 & 1,05 & 1,49 & \\
\hline & CS2B & 2 & 1,09 & 1,52 & \\
\hline C inf. & CS2B & 1 & 0,70 & 0,74 & \\
\hline $\mathbf{P}_{4}$ & CS2B & 1 & 0,72 & - & \\
\hline \multirow{2}{*}{$\mathbf{M}_{1}$} & CS1A & 1 & 1,17 & 0,74 & 0,86 \\
\hline & CS2B & 2 & 1,17 & 0,74 & 0,78 \\
\hline \multirow{2}{*}{$\mathbf{M}_{2}$} & CS1A & 2 & $1,09-1,25$ & 0,78 & 0,82 \\
\hline & CS2B & 1 & 1,23 & 0,74 & 0,80 \\
\hline$M_{3}$ & CS2B & 2 & $1,13-1,17$ & $0,66-0,70$ & $0,54-0,60$ \\
\hline
\end{tabular}

Tabla 2. Medidas de Eptesicus noctuloides de Casetón 1A (CS1A) y Casetón 2B (CS2B). ( $\mathrm{n}=$ número de restos; $\mathrm{L}=$ longitud; $\mathrm{A}=$ anchura; en molares inferiores, anchura del trigónido; $\mathrm{a}=$ anchura del talónido).

Measurements of Eptesicus noctuloides from Casetón $1 A(C S 1 A)$ and Casetón $2 B(C S 2 B)$. $(n=$ number of remains; $L=$ length; $A=$ width; in the lower molars, the width of the trigonid; $a=$ width of the talonid).

Mi: molar myotodonto (Menú y Sigé, 1971), con el talónido más ancho y más largo que el trigónido. Metacónido más alto que el paracónido; paralófido alto y suavemente recurvado. Talónido en vista labial más bajo que el trigónido. Hipoconúlido bien desarrollado.

$\mathbf{M}_{2}$ : similar al $\mathbf{M}_{1}$, pero algo más ancho y con el paracónido y el metacónido ligeramente más próximos entre sí.

$\mathbf{M}_{3}$ : talónido largo pero estrecho; el entocónido en la misma posición que en el $\mathrm{M}_{1} \mathrm{y}$ en el $\mathrm{M}_{2}$; postcréstida reducida a casi la mitad que en los molares anteriores; el hipocónido reducido en altura y retraído hacia una posición más próxima al entocónido. Hipoconúlido bien desarrollado, pero más pequeño que en el $\mathrm{M}_{1}$ y en el $\mathrm{M}_{2}$. Cíngulo recto en vista labial, ligeramente más grueso en la base del protocónido.

\section{Discusión}

Las especies del género Eptesicus son frecuentes en el Mioceno de Europa, aunque menos que las del género Myotis. Ambos géneros muestran diferencias en la morfología y desarrollo relativo de las cúspides y crestas de sus dientes, además de una fórmula dentaria diferente.

Hasta el momento se han descrito cuatro especies atribuidas al género Eptesicus en el Mioceno de Europa. Todas ellas presentan una talla superior a la que se observa en el material de Casetón 1A y de Casetón 2B, salvo E. noctuloides (Lartet, 1851) del yacimiento de Sansan (Baudelot, 1972). Al comparar el material de los dos niveles de Casetón con las descripciones de Baudelot (op. cit.), se comprueba una coincidencia total en la morfología. En cuanto a la talla, el material de Casetón $1 \mathrm{~A}$ y $2 \mathrm{~B}$ entra en el rango de variación de $E$. noctuloides de Sansan. Tan solo cabría señalar unos valores de longitud ligeramente mayores en los $\mathrm{M}^{2}$ de Casetón 1A y en los $\mathrm{M}_{3}$ de Casetón 2B.

E. aff. noctuloides de Sandelzhausen (Ziegler, 2000a) presenta molares inferiores más comprimidos, con trigónidos lingualmente más cerrados y talónidos más cortos; en el $\mathrm{M}_{3}$ el metacónido aparece desplazado lingualmente, de modo que las tres cúspides linguales no están alineadas, y la postcréstida está relativamente menos reducida, por lo que el talónido de $\operatorname{los} \mathrm{M}_{3}$ de Sandelzhausen (Ziegler, op. cit.) es más ancho que el talónido de los $\mathrm{M}_{3}$ de E. noctuloides de Sansan (Baudelot, 1972) o de Casetón 2B. En los molares superiores de $E$. aff. noctuloides de Sandelzhausen también se observan diferencias. Así, la postmetacresta es más alargada; el $\mathrm{M}^{\prime}$ presenta su lado labial relativamente más comprimido y el margen lingual es redondeado y estrecho. En cuanto a los caninos superiores, los de Sandelzhausen son muy similares a los de Casetón 1A y Casetón 2B, aunque con la cúspide basal del cíngulo algo menos desarrollada.

E. aurelianensis de Wintershof-West (MN3) (Ziegler, 1993) y Stubersheim 3 (Ziegler, 1994) es algo más grande que $E$. noctuloides y presenta molares inferiores con el talónido proporcionalmente más corto y una gran reducción distal del $\mathrm{M}^{3}$.

Los restos de E. noctuloides de las asociaciones de Casetón se diferencian de los de $M$. aff. minor por su talla ligeramente mayor, por el desarrollo del paralofo de los molares superiores, y por la mayor abertura lingual del trigónido en los molares inferiores. Además, en la vista labial de éstos últimos dientes, se observa que en $M$. aff. minor la base del talónido está algo hundida con relación a la base del trigónido.

\section{Eptesicus sp.}

Fig. 5, a-e.

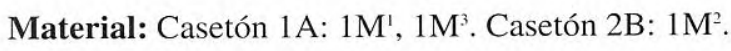

Medidas: Tabla 3.

\section{Descripción}

$\mathbf{M}^{1}$. Contorno rectangular. Metacono más desarrollado que el paracono. Sin paralofo ni metalofo. Postmetacresta alargada. La postprotocresta se arquea ligeramente en dirección labial, pero no cierra distalmente la protofosa. Aunque el único diente disponible está ligeramente deteriorado en la base del protocono, el cíngulo parece continuo en la base lingual de esta cúspide.

$\mathbf{M}^{2}$. Solo se conserva un fragmento de $\mathbf{M}^{2}$ procedente de Casetón 2B con el metacono completo y parte del paracono. 


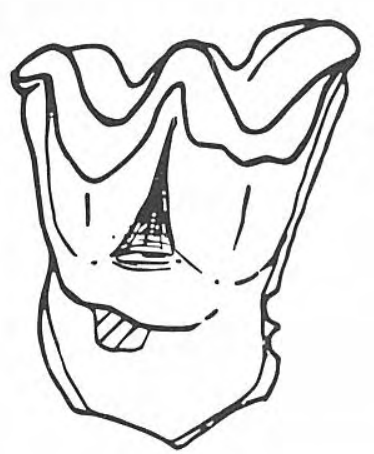

a

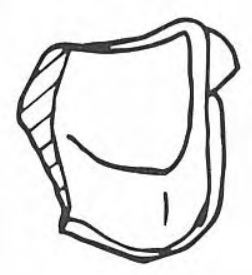

e

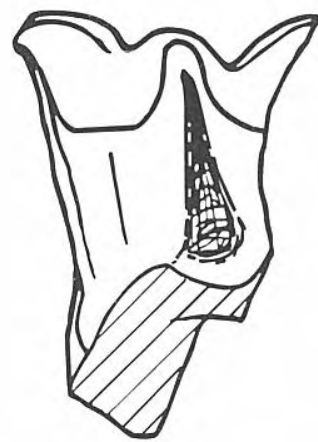

b

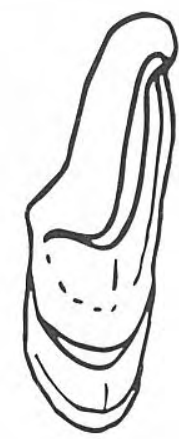

C

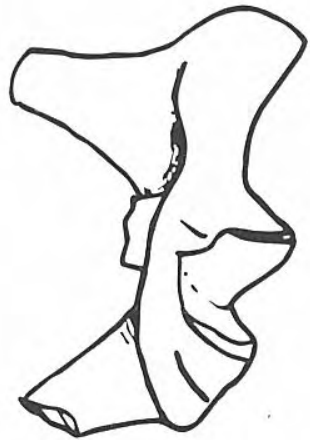

d

$1 \mathrm{~mm}$
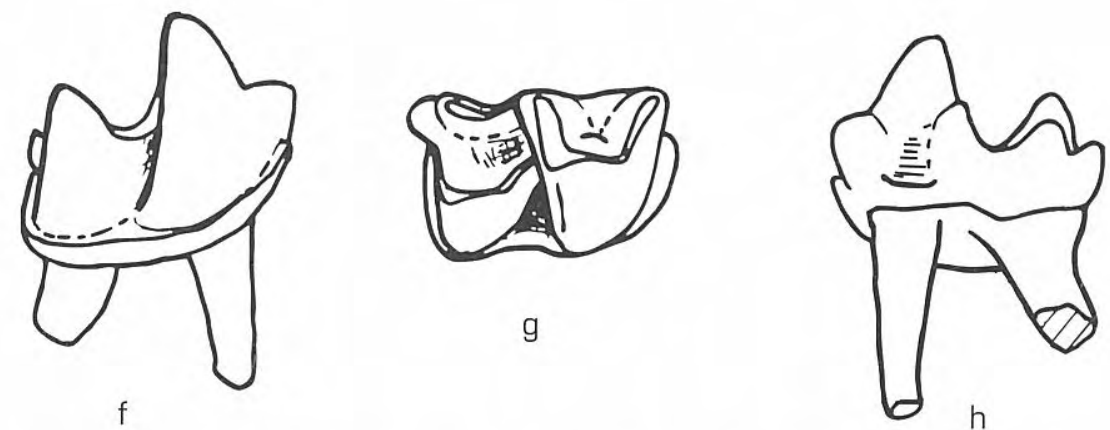

Figura 5. a-e. Eptesicus sp. a: $M^{1}$ izdo. (RGM 413935). b: $M^{2}$ dcho. (RGM 413964). c-d: M³ dcho. (RGM 413936)(c: vista oclusal; d: vista distal). e: $\mathrm{M}_{1-2}$ izdo. (RGM 413939). f-h. Hipposideridae indet.: $\mathrm{M}_{1}$ dcho. (RGM 413937) (f: vista labial; g: vista oclusal; h: vista lingual).

a-e. Eptesicus sp. a: left $M^{\prime}$ (RGM 413935). b: right $M^{2}$ (RGM 413964). c-d: right $M^{3}$ (RGM 413936) (c: occlusal view; $d$ : distal view). e: left $M_{1-2}\left(R G M\right.$ 413939). $f$-h. Hipposideridae indet.: right $M_{1}$ (RGM 413937) (f: labial view; g: occlusal view; : lingual view).

Concuerda tanto en su morfología como en la talla con el diente anteriormente descrito, aunque la forma del ectolofo permite reconocer que se trata de un segundo molar.

$\mathbf{M}^{3}$. Este diente presenta una fuerte reducción distal: la preparacresta y el paracono están bien desarrollados; la postparacresta, muy reducida, discurre en dirección distal. Mesostilo rudimentario. No hay indicios de metacono. El cíngulo lingual es continuo en la base del protocono.

\begin{tabular}{|l|c|c|c|c|}
\hline \multicolumn{2}{|l|}{} & $n$ & $L$ & $A$ \\
\hline$M^{1}$ & CS1A & 1 & 2,23 & $(2,66)$ \\
\hline$M^{2}$ & CS2B & 1 & - & - \\
\hline $\mathbf{M}^{3}$ & CS1A & 1 & 1,56 & 2,62 \\
\hline
\end{tabular}

Tabla 3. Medidas de Eptesicus sp. de Casetón 1A (CS1A) y Casetón $2 \mathrm{~B}(\mathrm{CS} 2 \mathrm{~B})$. ( $\mathrm{n}=$ número de restos; $\mathrm{L}=$ longitud; $\mathrm{A}=$ anchura).

Measurements of Eptesicus sp. from Casetón $1 A$ (CS1A) and Casetón $2 B(C S 2 B)$. ( $n=$ number of remains; $L=$ length; $A=$ width).
También se ha atribuido a Eptesicus sp. un fragmento de molar inferior izquierdo, concretamente un talónido myotodonto (Menú y Sigé, 1971), que por su tamaño se corresponde con los molares superiores anteriormente descritos.

\section{Discusión}

El conjunto de caracteres que presentan los dientes arriba descritos encaja con las morfologías que presentan las especies de talla grande del género Eptesicus (ver Menú, 1985). La fuerte reducción distal del $\mathrm{M}^{3}$ es también característica de algunos de los "eptesiformes" eurasiáticos de talla grande, por lo que parece justificado asignar estos restos a una especie de talla grande perteneciente al género Eptesicus.

Hasta el momento, Eptesicus campanensis Baudelot, 1970 es la única especie de talla grande del género Eptesicus descrita en el Mioceno de Europa. Esta especie se conoce a partir de una mandíbula y un canino superior del yacimiento de Sansan (Baudelot, 1972) y un canino superior de Povoa de Santarem (MN 7/8) (Antunes y Mein, 1977). Un molar superior procedente de las colecciones del Museo de Basilea y atribuido por Baudelot (1972) a esta especie, presenta una talla ligeramente inferior a la que se observa en los molares superiores de Eptesicus sp. de Casetón 1A y Casetón 2B. 
La escasez de material de esta forma grande del género Eptesicus en las asociaciones de Casetón, junto con los pocos restos descritos de E. campanensis no permite por el momento establecer la relación entre ambas especies.

Otra especie próxima en morfología al género Eptesicus, Pareptesicus priscus Zapfe, 1950 descrita en el yacimiento de Neudorf - Spalte de Checoslovaquia (MN6) (Zapfe, 1950) presenta en el $\mathrm{M}^{3}$ una fuerte reducción distal, similar a la que se observa en el fósil de Casetón 1A. Sin embargo, los molares parecen algo más cortos a nivel del protocono, especialmente el $\mathrm{M}^{3}$. Las medidas de los dientes, tomadas a partir de la figura 8 (Zapfe, op. cit.), indican una talla claramente inferior a la de los restos de Casetón 1A y 2B, por lo que se descarta una relación entre el género Pareptesicus y los restos del eptesiforme grande de Casetón 1A y Casetón 2B.

\section{Familia Hipposideridae Miller, 1907}

\section{Hipposideridae indet.}

Fig. $5, \mathrm{f}-\mathrm{h}$

Material: Casetón 1A: 1M

\section{Medidas: Tabla 4.}

\section{Descripción}

Se trata de un molar inferior nyctalodonto (Menú y Sigé, 1971), concretamente un $M_{1}$ por la abertura lingual del trigónido. En vista oclusal se observa que el talónido es algo más corto que el trigónido, aunque más ancho que éste debido a la posición más labial del hipocónido; la entocréstida es cóncava hacia el margen lingual y el hipoconúlido es grande. En vista labial se observa que el cíngulo, de grosor intermedio, regular y sin inflexiones, discurre continuo desde la base del paracónido hasta la base del hipoconúlido.

\section{Discusión}

El conjunto de caracteres que presenta este diente permite relacionarlo con dos géneros diferentes dentro de la familia Hipposideridae: Hipposideros Miller, 1907 y Asellia Gray, 1838. De entre los tres subgéneros de Hipposideros con registro en el Mioceno, se puede excluir que pertenezca al subgénero Pseudorhinolophus Schlosser, 1887, ya que en éste la entocréstida está poco desarrollada. En cuanto al subgénero Syndesmotis Peters, 1871, la única especie fósil incluida en este subgénero, Hipposideros (S.) vetus (Lavocat, 1961) es de menor talla y presenta molares inferiores proporcionalmente más alargados, con el trigónido más abierto lingualmente. Por último, el subgénero Brachipposideros Sigé, 1968 presenta molares inferiores muy similares al de Casetón 1A. Sin embargo, todas las especies de este subgénero descritas en el Mioceno difieren tanto en la talla como en la morfología con el fósil de Casetón 1A. Hipposideros (B.) dechaseauxi Sigé, 1968 es algo mayor que el fósil de Casetón 1A y presenta molares inferiores más alargados y estrechos, con la entocréstida larga y

\begin{tabular}{|c|c|c|c|c|c|}
\hline \multicolumn{2}{|l|}{} & $n$ & L & A & a \\
\hline$M_{1}$ & CS1A & 1 & 1,68 & 1,01 & 1,01 \\
\hline
\end{tabular}

Tabla 4. Medidas de Hipposideridae indet. de Casetón 1A. ( $\mathrm{n}$ = número de restos; $\mathrm{L}=$ longitud; $\mathrm{A}=$ anchura del trigónido; a = anchura del talónido).

Measurements of Hipposideridae indet. from Casetón 1A. ( $n=$ number of remains; $L=$ length; $A=$ width of the trigonid; $a=$ width of the talonid).

recta. H. (B.) branssatensis Hugueney, 1965 y $H$. (B.) aguilari Legendre, 1982 son por el contrario de menor talla, y los talónidos de los molares inferiores son más alargados y estrechos. Dentro del subgénero Brachipposideros, Hipposideros (B.) collongensis (Déperet, 1892) es la forma que presenta la morfología más próxima a la del fósil de Casetón 1A, aunque también es de menor talla.

Por otro lado, la única especie fósil del género Asellia, A. mariatheresae Mein, 1958 también presenta molares inferiores que coinciden tanto en morfología como en la talla con las del $\mathrm{M}_{1}$ de Casetón 1A. Este único resto no presenta caracteres que permitan concluir a cuál de los dos géneros pertenece, si al género Hipposideros, subgénero Brachipposideros, o al género Asellia, por lo que queda asignado a la familia Hipposideridae, en la que están agrupados ambos géneros.

\section{CONCLUSIONES}

El estudio de los restos fósiles de Quirópteros de los yacimientos de Casetón ha permitido reconocer cuatro especies diferentes en Casetón 1A; tres de ellas representadas en el yacimiento de Casetón 2B.

En ambas asociaciones se han identificado restos de dos especies diferentes pertenecientes al género Eptesicus. La presencia de este género en los yacimientos de Casetón 1A y 2B permite ampliar su registro en España al Mioceno Medio, pues hasta el momento sólo estaba citado en el Cuaternario (Sevilla, 1991).

La especie mejor representada, en cuanto a número de restos, tanto en Casetón 1A como en Casetón 2B, es Eptesicus noctuloides. Esta especie, o formas morfológicamente próximas a ella, se ha citado en diversos yacimientos del Mioceno Medio de Europa. El material que se ha atribuido a esta especie en Casetón 1A y en Casetón 2B no muestra diferencias importantes con el material de la localidad tipo, el yacimiento de Sansán en Francia (Baudelot, 1972). La segunda especie atribuida al género Eptesicus en los yacimientos de Casetón está pobremente representada, y se trata de una forma de tamaño similar o algo superior al de $E$. campanensis, una especie poco frecuente, citada en los yacimientos del Mioceno Medio de Sansan (Baudelot, op. cit.) y Povoa de Santarém (Antunes y Mein, 1977). 
El género Myotis está representado en Casetón 1A y en Casetón 2B por una única especie de talla pequeña, Myotis aff. minor. Aunque se han descrito varias especies pequeñas del género Myotis en el Mioceno de Europa, tales como $M$. murinoides y $M$. elegans (véase Sigé y Legendre, 1983), el material de Casetón 1A y Casetón 2B muestra, a pesar de la diferencia de edad, una mayor proximidad morfológica con la especie del Oligoceno terminal (MP29), Myotis minor Ziegler, 2000b. No obstante, $M$. aff. minor de Casetón 1A y Casetón 2B difiere en algunos caracteres de $M$. minor, entre los que cabe destacar la ausencia de metalofo en los molares superiores y el mayor desarrollo del hipoconúlido en el $\mathrm{M}_{3}$.

La familia Hipposideridae, diversa y bien representada en el Mioceno, tanto en yacimientos cársticos como fluvio-lacustres, está representada por un único resto en Casetón $1 \mathrm{~A}$, que no ha sido posible relacionar con un género particular dentro de la familia.

Las asociaciones de Casetón 1A y Casetón 2B se caracterizan por la escasez de restos de quirópteros y la baja diversidad que éstos representan. En ambas asociaciones dominan los vespertiliónidos y, dentro de éstos, dos especies constituyen prácticamente la totalidad del material. Myotis aff. minor y E. noctuloides forman el $87 \%$ de los restos de quirópteros en Casetón 1A y el $95 \%$ en Casetón 2B. Las asociaciones pobres en restos de quirópteros, dominadas por una o dos especies de la familia Vespertilionidae, son frecuentes en los yacimientos fluvio-lacustres del Mioceno Medio y Superior de Europa. La combinación de dos especies de pequeño tamaño, una del género Myotis y otra del género Eptesicus, como formas dominantes entre los quirópteros representados en este tipo de asociaciones, se ha descrito en otros yacimientos europeos de edad similar, tales como Sandelzhausen C3-E (MN5) (Ziegler, 2000a) y Sansan (MN6) (Baudelot, 1972).

Por último cabe señalar que aunque los roedores fósiles representados en las asociaciones de Casetón 1A y 2B indican un ambiente relativamente cálido para la época en la que se produjo el depósito, con una humedad relativa media y un paisaje de grandes espacios abiertos (Daams et al., 1988), los restos del género Eptesicus, cuyas especies se distribuyen en la actualidad en hábitats boscosos, parecen indicar la existencia de alguna zona de arbolado en las proximidades del yacimiento, ya que los espacios abiertos proporcionan escasos refugios a los quirópteros de éste género.

\section{AGRADECIMIENTOS}

Mi agradecimiento a las numerosas personas que tomaron parte en las campañas de excavación en las áreas de Calatayud-Teruel, durante las cuales fue recogido el material que se describe en este trabajo, y muy en particular a los dres. Daams y Freudenthal, que me confiaron el material de quirópteros para su estudio. Las excavaciones en las que se recogió este material fueron financiadas en parte por el proyecto PB92-0013 de la DGICYT.

\section{BIBLIOGRAFÍA}

Adrover, R. 1968. Los primeros micromamíferos de la cuenca valenciana en Buñol (nota preliminar). Acta Geológica Hispánica, 3(3), 78-80.

Adrover, R. 1972. Yacimiento de micromamíferos en Navarrete del Río (Provincia de Teruel, España). Acta Geológica Hispánica, 7(6), 176-177.

Adrover, R. 1975. Principales yacimientos paleomastozoológicos de la provincia de Teruel y su posición estratigráfica relativa. Trabajos del NeógenoCuaternario, 4, 31-48.

Adrover, R., Mein, P. y Moissenet, E. 1978. Nuevos datos sobre la edad de las formaciones continentales neógenas de los alrededores de Teruel. Estudios geológicos, 34, 205-214.

Aguilar, J.P., Brandy, L.D. et Thaler, L. 1984. La migration de Salobreña (Sud de l'Espagne) et le problème de la migration messinienne. Paléobiologie continentale, 14 (2), 3-17.

Agustí, J. and Moyà-Solà, S. 1990. Neogene- Quaternary mammalian faunas of the Balearics. Atti dei convegni lincei, 85, 459-468.

Alcalá, L., Sesé, C., Herráez, E. y Adrover, R. 1991. Mamíferos del Turoliense inferior de Puente Minero (Teruel, España). Boletín de la Real Sociedad Española de Historia Natural (sección Geología), 86, 205-251.

Alcalá, L., Alonso Zarza, A.M., Álvarez Sierra, M.A., Azanza, B., Calvo, J.P., Cañaveras, J.C., van Dam, J.A., Garcés, M., Krijgsman, A.J., van der Meulen, A.J., Morales, J., Peláez-Campomanes, P., Pérez González, A., Sánchez Moral, S., Sancho, R. y Sanz Rubio, E. 2000. El registro sedimentario y faunístico de las cuencas de Calatayud-Daroca y Teruel. Evolución paleoambiental y paleoclimática durante el Neógeno. Revista de la Sociedad Geológica de España, 13, 323343.

Antunes, M.T. et Mein, P. 1977. Contributions à la paléontologie du Miocène moyen continentale du Bassin du Tage. III. Mammifères. Povoa de Santarem, Pero Filho et Choes (Secorio). Conclusions générales. Ciencias da Terra (U.N.L.), 3, 143-165.

Baudelot, S. 1970. Complément à l'étude des Micromammifères récoltés dans le Miocène de la Romieu (Gers). Comptes Rendus sommaires de la Societé Géologique de France, 8, 303-304

Baudelot, S. 1972. Etude des Chiroptères, insectivores et rongeurs du Miocène de Sansan (Gers). Thèse d'Etat, Université Paul Sabatier. Tolouse. (Inédita). 364 pp.

Daams, R. and Freudenthal, M. 1988. Synopsis of the Dutch-Spanish collaboration program in the Aragonian type area. 1975-1986. Scripta Geologica, Special Issue, 1, 3-18.

Daams, R., Freudenthal, M. and Álvarez, M.A. 1987. Ramblian, a new stage for continental deposits of Miocene age. Geologie en Mijnbow, 65(4), 297-308.

Daams, R., Freudenthal, M. and Van der Meulen, A.J. 1988. Ecostratigraphy of micromammal faunas from the Neogene of Spain. Scripta Geologica, Special Issue, $\mathbf{1}$, 287-302. 
Daams, R., Van der Meulen, A.J., Álvarez Sierra, M.A., Peláez-Campomanes, P., Calvo, J.P., Alonso Zarza, M.A. and Krijgsman, W. 1999. Stratigraphy and sedimentology of the Aragonian (Early to Middle Miocene) in its type area (North-Central Spain). Newsletters in Stratigraphy, 37(3), 103-139.

Déperet, C. 1892. La Faune de Mammifères miocènes de La Grive Saint-Alban (Isère) et de quelques autres localités du Bassin du Rhône. Archives du Muséum d'Histoire naturelle de Lyon, 5(2), 1-95.

Gaillard, C. 1899. Mammifères miocènes nouveaux ou peux connus de La Grive Saint-Alban. Archives du Muséum d'Histoire naturelle de Lyon, 7(2), 1-79.

Hugueney, M. 1965. Les chiroptères du Stampien supérieur de Coderet-Branssat (Allier). Documents du Laboratoire de Geologie de la Faculté des Sciences de Lyon, 9, 97127.

Lartet, E. 1851. Notice sur la Colline de Sansan. 1er vol. J.A. Portes, Auch. 47 pp.

Lavocat, R. 1961. Le gisement de vertébrés miocènes de Beni Mellal (Maroc). Étude systématique de la faune de mammifères. Notes et Mémoires du Service géologique de Maroc, 155, 29-94.

Legendre, S. 1982. La faune de micromammifères du gisement burdigalien de Port-la-Nouvelle (aude). Compléments et indications paléoécologiques. Bulletin de la Societé géologique de France, 7(2), 383-387.

Martínez Salanova, J. 1987. Estudio paleontológico de los Micromamíferos del Mioceno inferior de Fuenmayor ( $\mathrm{La}$ Rioja). Publicaciones del Instituto de Estudios Riojanos, 99 pp.

Mein, P. 1958. Les Mammifères de la faune sidérolithique de Vieux-Collonges. Nouvelles Archives du Muséum d'Histoire naturelle de Lyon, 5, 1-122.

Mein, P. 1964. Chiroptera (Miocène) de Lissieu (Rhône). Compte Rendus 89 Congrès Nationale Societé savantes Secc. Sciences, 237-253.

Menú, H. 1985. Morphotypes dentaires actuels et fossiles des Chiroptères Vespertilioninés. $1^{\mathrm{e}}$. Partie : étude des morphologies dentaires. Palaeovertebrata, 15(2), 71 128.

Menú, H. 1987. Morphotypes dentaires actuels et fossiles des Chiroptères Vespertilioninés. 2eme Partie : Implications systematiques et phylogéniques. Palaeovertebrata, 17(3), 77-150.

Menú, H. et Popelard, J.B. 1987. Utilisation des caractères dentaires pour la détermination des Vespertilioninés de l'ouest européen. Le Rhinolophe, 4, 1-88.

Menú, H. et Sigé, B. 1971. Nyctalodontie et myotodontie, importants caractères de grades évolutifs chez les Chiroptères entomophages. Comptes rendus hebdomadaires Séances de l'Académie des Sciences de Paris, 272, 1735-1738.

Rachl, R. 1983. Die Chiroptera (Mammalia) aus den mittelmiozänen Kalken des Nördlinger Rieses (Süddeutschland). Dissertation zur Doktorgrades. Ludwig-Maximilians-Universität. München. (Inédita). 284 pp.

Schlosser, M. 1887. Die Affen, Lemuren, Chiropteren, etc. des europäisches Tertiärs. I. Teil. Beiträge zur
Paläontologie des Oesterreich-Ungarns und des Orients, 6, 55-79.

Sesé, C. 1986. Chiroptera (Mammalia) del yacimiento del Mioceno medio de Escobosa de Calatañazor. Estudios Geológicos, 42, 33-39.

Sevilla, P. 1986. Identificación de los principales quirópteros ibéricos a partir de sus dientes aislados. Valor sistemático de los caracteres morfológicos y métricos dentarios. Doñana, Acta Vertebrata, 13, 111-130.

Sevilla, P. 1988. Estudio Paleontológico de los Quirópteros del Cuaternario español. Paleontologia i Evolució, 22. 113-233.

Sevilla, P. 1991. Murciélagos fósiles de España. In: Los murciélagos de España y Portugal (Eds. J. Benzal y O. de Paz). Ediciones del Ministerio de Agricultura, Pesca y Alimentación, Colección Técnica, Madrid, 23-36.

Sevilla, P. and López Martínez, N. 1986. Comparative systematic value between dental and external/skeletal features in Western European Chiroptera. Mémoires du Muséum National d'Histoire Naturelle Paris (série C), 53, 255-266.

Sigé, B. 1968. Les Chiroptères du Miocène inférieur de Bouzigues. I. Étude systématique. Palaeovertebrata, 1(3), 65-133.

Sigé, B. et Legendre, S. 1983. L'histoire des peuplements des chiroptères du bassin méditerranéen: l'apport comparé des remplissages karstiques et des dépôts fluvio-lacustres. Mémoires Biospéologie, 10, 209-225.

Storch, G. 1974. Quartäre Fledermaus-Faunen von der Insel Malta. Senckenbergiana lethaea, 55, 407-434.

Storch, G. 1999. Order Chiroptera. In: The Miocene Land Mammals of Europe (Eds. G. E. Rössner and K. Heissig). Verlag Dr. Friedrich Pfeil, München, 81-90.

Van der Meulen, A.J. and Daams, R. 1992. Evolution of Early-Middle Miocene rodent faunas in relation to longterm palaeoenvironmental changes. Palaeogeography, Palaeoclimatology, Palaeoecology, 93, 227-253.

Zapfe, H. 1950. Die Fauna der Miozänen Spaltenfüllung von Neudorf a. D. March (CSR). Chiroptera. Sitzungsberichten der Österreicher Akademie der Wissenschaften, mathematisch- naturwissenschaft Kl., Abteilung 1, 159, 51-64.

Ziegler, R. 1993. Die Chiroptera (Mammalia) aus dem Untermiozän von Wintershof-West bei Eichstätt (Bayern). Mitteilungen der Bayerische Staatssamlungen für Paläontologie und historische Geologie, 33, 110-154.

Ziegler, R. 1994. Die Chiroptera (Mammalia) aus dem Untermiozän von Stubersheim 3 (Baden-Württemberg). Münchner Geowissenschaftlichen Abhandlungen (A), 26, 97-116.

Ziegler, R. 2000a. The Miocene Fossil-Lagerstätte Sandelzhausen, 17. Marsupialia, Lipotyphla and Chiroptera (Mammalia). Senckenbergiana lethaea, 80, 81-127.

Ziegler, R. 2000b. The bats (Chiroptera, Mammalia) from the Late Oligocene Fissure Fillings Herrlingen 8 and Herrlingen 9 near Ulm (Baden-Württemberg). Senckenbergiana lethaea, 80, 647-683.

Manuscrito recibido: 11 de octubre, 2001 Manuscrito aceptado: 22 de abril, 2002 